\title{
Inhaled Nitric Oxide Improves Gas Exchange and Lowers Pulmonary Vascular Resistance in Severe Experimental Hyaline Membrane Disease
}

\author{
JOHN P. KINSELLA, D. DUNBAR IVY, AND STEVEN H. ABMAN
}

Department of Pediatrics, Sections of Neonatology, Cardiology, and Pulmonary Medicine, The Children's Hospital and the University of Colorado School of Medicine, Denver, Colorado 80262

\section{ABSTRACT}

To determine the effects of inhaled nitric oxide (NO) on pulmonary hemodynamics and gas exchange in experimental hyaline membrane disease (HMD), we studied 16 premature lambs $(0.78 \mathrm{term})$ in two separate protocols. All animals were treated with exogenous surfactant before mechanical ventilation. In protocol 1 , we measured the acute response to brief treatment with inhaled NO (20 ppm, $20 \mathrm{~min}$ ) after $2 \mathrm{~h}$ of mechanical ventilation with fraction of inspired oxygen of $1.00(n=5)$. After $2 \mathrm{~h}$, brief NO treatment lowered pulmonary vascular resistance from $0.26 \pm 0.05$ to $0.16 \pm 0.03 \mathrm{~mm} \mathrm{Hg} \cdot(\mathrm{mL} / \mathrm{min})^{-1}(p<0.01)$ and improved gas exchange (arterial $\mathrm{Po}_{2}, 44 \pm 9 \mathrm{~mm} \mathrm{Hg}$ baseline to $168 \pm 45 \mathrm{~mm} \mathrm{Hg} \mathrm{NO}, p<0.01$; arterial $\mathrm{PCO}_{2} 45$ $\pm 5 \mathrm{~mm} \mathrm{Hg}$ baseline to $35 \pm 4 \mathrm{~mm} \mathrm{Hg} \mathrm{NO}, p<0.05)$. In protocol 2 , to determine whether early and continuous treatment with inhaled NO could sustain improvement in gas exchange and pulmonary hemodynamics in severe HMD, we compared the physiologic effects of ventilation with high inspired oxygen concentrations for $3 \mathrm{~h}$ with NO (20 ppm, $n=6$ ) and without NO (controls, $n=5$ ). After 3 $h$, the NO treatment group had sustained reduction in pulmonary vascular resistance $(0.10 \pm 0.01 \mathrm{~mm} \mathrm{Hg} \cdot(\mathrm{mL} /$ $\mathrm{min})^{-1} \mathrm{NO}$ versus $0.25 \pm 0.04 \mathrm{~mm} \mathrm{Hg} \cdot(\mathrm{mL} / \mathrm{min})^{-1}$ con- trol, $p<0.05$ ), increased left pulmonary artery blood flow $(204 \pm 24 \mathrm{~mL} / \mathrm{min}$ NO versus $109 \pm 15 \mathrm{~mL} / \mathrm{min}$ control, $p$ $<0.05)$, and increased arterial $\mathrm{Po}_{2}(114 \pm 27 \mathrm{~mm} \mathrm{Hg} \mathrm{NO}$ versus $36 \pm 11 \mathrm{~mm} \mathrm{Hg}$ control, $p<0.05)$. We conclude that inhaled NO causes marked and sustained improvement in pulmonary hemodynamics and gas exchange in severe experimental HMD. We speculate that pulmonary vasoconstriction and ventilation/perfusion abnormalities contribute to the pathophysiology of severe respiratory failure in preterm newborns, and early treatment with inhaled NO may be effective in clinical management of selected premature patients with HMD. (Pediatr Res 36: 402-408, 1994)

NO, nitric oxide

\section{Abbreviations}

HMD, hyaline membrane disease

PVR, pulmonary vascular resistance

$\mathbf{Q}_{\text {LPA }}$, left pulmonary artery blood flow

PIP, peak inspiratory pressure

PEEP, positive end expiratory pressure

$\mathrm{FiO}_{2}$, fraction of inspired oxygen

$\mathbf{P a O}_{2}$, arterial partial pressure of oxygen

$\mathbf{P a c o}_{2}$, arterial partial pressure of carbon dioxide
Previous studies have demonstrated the vital role of endogenous NO production in decreasing PVR during the transition of the pulmonary circulation at birth in the near-term ovine fetus (1), the potent pulmonary vasodilator effects of inhaled NO in the late-gestation and newborn lamb (2-4), and the potential role of inhaled NO in the treatment of term human neonates with persistent pulmonary hypertension of the newborn (5-8). However, most of these studies examined near-term and term sub-

Received for rapid publication April 21, 1994; accepted May 17, 1994

Correspondence: John P. Kinsella, M.D., Division of Neonatology, Box B-070, The Children's Hospital, 1056 E. 19th Ave., Denver, CO, 80218-1088.

Supported in part by grants from the National Institutes of Health (HL-01932, HL-41012, HL-46481), the Basil O'Connor Starter Scholar Research Award from the March of Dimes Birth Defects Foundation, and the Bugher Physician-Scientist Award. jects. Mechanisms of pulmonary vasoregulation in the premature fetus and postnatal pulmonary adaptation in the premature newborn have received little attention.

After premature birth, severe respiratory failure is often the result of surfactant deficiency, and treatment with exogenous surfactant can cause dramatic improvements in oxygenation. However, exogenous surfactant therapy results in suboptimal responses in up to $50 \%$ of human newborns thought to have HMD (9), suggesting that other problems of prematurity $(e . g$. structural lung immaturity or altered vascular responses to dilator stimuli) or complications of standard interventions contribute to respiratory failure.

We have recently reported that endogenous NO production modulates basal pulmonary vascular tone as early as $78 \%$ of term gestation and contributes to the increase in pulmonary blood flow after delivery in extreme 
prematurity (10). In addition, inhaled NO caused marked increases in pulmonary blood flow after NO synthase inhibition, demonstrating marked responsiveness of the vascular smooth muscle cell to NO very early in gestation. Whether pulmonary vasoregulation in the premature subject is altered during prolonged mechanical ventilation with high inspired oxygen concentrations is unknown.

The premature lamb has been extensively studied as a model of severe HMD (11). Survival with exogenous surfactant treatment and mechanical ventilation at delivery varies depending on the gestational age of the lamb and the type of surfactant given $(12,13)$. We have observed worsening gas exchange and increased PVR in premature lambs delivered at $115 \mathrm{~d}$ gestation $(0.78$ term) when mechanical ventilation was continued beyond 60-90 min after birth, despite treatment with exogenous surfactant at delivery. We hypothesized that exogenous (inhaled) NO could reverse the disturbances in gas exchange and pulmonary hemodynamics associated with prolonged mechanical ventilation of the extremely immature lung. To test these hypotheses, we delivered ovine fetuses at $78 \%$ of term gestation in two separate protocols to measure responses to acute and sustained NO inhalation during mechanical ventilation.

\section{METHODS}

Mixed-breed (Columbia-Rambouillet) pregnant ewes were used in this study. All procedures and protocols were reviewed and approved by the Animal Care and Use Committee at the University of Colorado Health Sciences Center.

This study includes two separate protocols that examine the effects of inhaled NO on pulmonary hemodynamics and gas exchange in this premature ( $115 \mathrm{~d}$ gestation, 0.78 term; term $=147 \mathrm{~d}$ ) ovine model of severe HMD. In protocol 1 , we studied the effects of brief treatment with inhaled NO after $2 \mathrm{~h}$ of mechanical ventilation $(n=5$ animals). In protocol 2 , we measured the effects of inhaled NO therapy initiated after delivery on pulmonary hemodynamics and gas exchange over a 3 -h period of mechanical ventilation ( $n=6$ animals), compared with controls ( $n=5$ animals).

\section{Surgical Preparation}

The following methods have been previously described $(2,14)$. Ewes were sedated with i.v. pentobarbital sodium $(2-4 \mathrm{~g}$ total dose) and anesthetized with intrathecal tetracaine hydrochloride ( $1 \%$ solution, $3 \mathrm{mg}$ ). Under sterile conditions, a uterine incision was made and the left forelimb of the fetal lamb was delivered. A skin incision was made in the axilla of the left fetal forelimb after local infiltration with lidocaine ( $1 \%$ solution, $2-3 \mathrm{~mL}$ ). Polyvinyl catheters (20 gauge; Martech Medical Products, Lansdale, PA) were advanced into the ascending aorta through the axillary artery and into the superior vena cava through the axillary vein. A left thoracotomy was performed, exposing the heart and great vessels. A cath- eter was inserted into the main pulmonary artery by direct puncture through purse-string sutures. This catheter was guided into position with a 14-gauge i.v. placement unit (Angiocath; Travenol, Deerfield, IL), and secured by tightening the purse-string suture as the introducer was withdrawn. The main pulmonary artery catheter was inserted between the ductus arteriosus and the pulmonic valve. A left atrial catheter was inserted in the medial portion of the left atrial appendage. An ultrasonic flow transducer $(6 \mathrm{~mm}$, Transonic Systems Inc., Ithaca, NY) was placed around the left pulmonary artery to measure blood flow to the left lung.

\section{Study Design-General}

After stabilization of physiologic parameters, pancuronium was administered to the fetus $(0.1 \mathrm{mg} / \mathrm{kg})$, the fetal head was exteriorized, and a tracheotomy was performed with placement of an endotracheal tube $(3.0 \mathrm{~mm}$ inner diameter). All animals were treated with exogenous surfactant (Infasurf, kindly provided by E. A. Egan, M.D.) at an estimated dose of $3 \mathrm{~mL} / \mathrm{kg}$ (105 mg phospholipid $/ \mathrm{kg}$ ) before the first breath. Mechanical ventilation was initiated with a continuous-flow, time-cycled, pressurelimited, neonatal ventilator at the following settings: PIP, $35 \mathrm{~cm} \mathrm{H}_{2} \mathrm{O}(3.4 \mathrm{kPa})$; PEEP, $6 \mathrm{~cm} \mathrm{H}_{2} \mathrm{O}(0.6 \mathrm{kPa})$; rate, 30 breaths per minute; inspiratory time, $1.0 \mathrm{~s}$; and $\mathrm{FiO}_{2}$, 1.00. After $30 \mathrm{~min}$ of mechanical ventilation, the umbilical cord was ligated and a 5\% dextrose solution was infused to provide $10 \mathrm{~mL} / \mathrm{h}$ crystalloid and $1 \mathrm{mg} / \mathrm{kg} / \mathrm{h}$ pentobarbital.

Mechanical ventilator settings were modified during the course of studies based on results of postductal arterial blood gas samples. Changes in PIP were determined by measurements of $\mathrm{PaCO}_{2}$. If $\mathrm{PaCO}_{2}$ was $<35 \mathrm{~mm} \mathrm{Hg} \mathrm{(4.7}$ $\mathrm{kPa})$, then the PIP was reduced to $30 \mathrm{~cm} \mathrm{H}_{2} \mathrm{O}(2.9 \mathrm{kPa})$. If subsequent measurements of $\mathrm{PaCO}_{2}$ were $<35 \mathrm{~mm} \mathrm{Hg}$ $(4.7 \mathrm{kPa})$, then the PIP was reduced to $25 \mathrm{~cm} \mathrm{H}_{2} \mathrm{O}(2.5$ $\mathrm{kPa})$. The maximum PIP delivered was $35 \mathrm{~cm} \mathrm{H}_{2} \mathrm{O}(3.4$ $\mathrm{kPa})$. If $\mathrm{PaCO}_{2}$ was greater than $45 \mathrm{~mm} \mathrm{Hg}(6 \mathrm{kPa})$, then the ventilator rate was increased to a maximum of 60 breaths/min. The inspiratory time was then decreased to maintain an inspiratory to expiratory ratio of $\leq 1.0$. PEEP was changed according to $\mathrm{PaO}_{2}$. If $\mathrm{PaO}_{2}$ was $<100 \mathrm{~mm} \mathrm{Hg}$ $(13.3 \mathrm{kPa})$, PEEP was maintained at $6 \mathrm{~cm} \mathrm{H}_{2} \mathrm{O}(0.6 \mathrm{kPa})$. With $\mathrm{PaO}_{2}>100 \mathrm{~mm} \mathrm{Hg}(13.3 \mathrm{kPa})$, PEEP was decreased to $5 \mathrm{~cm} \mathrm{H} \mathrm{H}_{2} \mathrm{O}(0.5 \mathrm{kPa})$. If $\mathrm{PaO}_{2}$ was $>200 \mathrm{~mm} \mathrm{Hg}(26.7$ $\mathrm{kPa}), \mathrm{PEEP}$ was decreased to $4 \mathrm{~cm}_{2} \mathrm{O}(0.4 \mathrm{kPa})$. The management strategy was guided by target $\mathrm{PaCO}_{2}$ and $\mathrm{PaO}_{2}$ values, with guidelines for ventilator adjustment as described above. We did not attempt to correct metabolic acidemia with infusions of base in these experiments. Main pulmonary artery, aortic, and left atrial catheters were connected to a Gould-Statham P23 ID pressure transducer (Gould, Inc., Oxnard, CA). Calibrations of pressure transducers were performed with a mercury column manometer. $Q_{L P A}$ and heart rate were measured using the ultrasonic flow transducer. PVR was calculated 
as (pulmonary artery pressure - left atrial pressure)/ $\mathrm{Q}_{\mathrm{LPA}}$ in $\mathrm{mm} \mathrm{Hg} \cdot(\mathrm{mL} / \mathrm{min})^{-1}$. Blood samples for $\mathrm{pH}$, $\mathrm{Po}_{2}, \mathrm{PCO}_{2}$, percent oxygen saturation, and percent methemoglobin were withdrawn anaerobically into Natelson glass pipettes and analyzed at $39.5^{\circ} \mathrm{C}$ using a Radiometer OSM3 blood gas analyzer (Copenhagen, Denmark). Blood $\mathrm{Hb}$ concentration and oxyhemoglobin saturation were measured colorimetrically in duplicate using a hemoximeter (Radiometer).

The NO gas (Airco, Riverton, NJ) used in these experiments was certified at a concentration of $450 \mathrm{ppm}$ NO (chemiluminescence method) with less than $1 \%$ contamination by other oxides of nitrogen. The NO tank was specially equipped with a stainless steel regulator and low flow meter for delivering finely gauged flow rates. NO was introduced into the afferent limb of the ventilator circuit through a $1 / 4 \times 1 / 4$-inch luer adaptor fitted within 1 $m$ of the endotracheal tube, thus mixing with the fixed flow rate of circuit gas $(10 \mathrm{~L} / \mathrm{min})$. The rate of NO flow was changed to yield an inspired NO concentration of 20 ppm. The resulting concentrations of inhaled NO were verified using chemiluminescence (Thermo Environmental Instruments, model 14A, Franklin, MA) or an electrochemical sensor calibrated against a reference NO tank (Sensorstik, Exidyne Instruments, Philadelphia, PA).

\section{Experimental Design}

Protocol 1. Effects of brief treatment with inhaled NO on pulmonary hemodynamics and gas exchange after $2 \mathrm{~h}$ of ventilation in the preterm lamb $(n=5$, weight $=1.73$ $\pm 0.11 \mathrm{~kg}$ ). After at least $1 \mathrm{~h}$ of recovery and stabilization of physiologic parameters, baseline hemodynamic and arterial blood gas measurements were recorded. An endotracheal tube was placed by tracheostomy and surfactant was instilled before the first mechanical ventilator breath. Mechanical ventilation was initiated (as described above); after $2 \mathrm{~h}$, inhaled NO (20 ppm) was delivered for $20 \mathrm{~min}$. Hemodynamic and arterial blood gas measurements were repeated and the NO was then discontinued. Mechanical ventilator settings were kept constant immediately before, during, and after NO treatment.

Protocol 2. Effects of early inhaled NO treatment on pulmonary hemodynamics and gas exchange during $3 h$ of mechanical ventilation (NO treatment group, $n=6$; controls, $n=5$ ). After recovery from surgery, baseline hemodynamic and arterial blood gas measurements were recorded. An endotracheal tube was placed, surfactant instilled, and mechanical ventilation initiated (as described above). In the NO treatment group, inhaled NO (20 ppm) was administered throughout the 3-h study period. All animals were treated with $\mathrm{FiO}_{2}=1.00$ (due to blending of the NO mixture with inspired gases, measured $\mathrm{FiO}_{2}$ for the $\mathrm{NO}$ treatment group was 0.94).

After the study, animals were killed with T-61 euthanasia solution (American Hoechst, Somerville, NJ). Fetal weight was recorded and appropriate catheter placement was verified.

\section{Statistical Analysis}

Statistical comparisons of continuous variables in protocol 1 were performed using one-way repeated measures analysis of variance. Where significant differences were identified, post-hoc analysis was performed using Fisher's least significant difference test. The statistical analysis of differences between the NO treatment group and control group in protocol 2 was performed using two-way analysis of variance for repeated measures (with time and treatment group identified as independent variables and the interaction between them analyzed). Comparisons of responses to each intervention (between treatment groups) at the $3-\mathrm{h}$ time point in protocol 2 were performed using the $t$ test. The level of statistical significance was set at $p<0.05$; results are reported as mean \pm SEM.

\section{RESULTS}

\section{Protocol 1}

Effects of brief treatment with inhaled NO on pulmonary hemodynamics and gas exchange after $2 h$ of ventilation in the preterm lamb $(n=5)$. Mechanical ventilation after surfactant treatment with $\mathrm{FiO}_{2}=1.00$ increased $\mathrm{PaO}_{2}$ 9.6-fold from baseline. However, despite continued ventilation, $\mathrm{PaO}_{2}$ progressively decreased over the subsequent 2-h study period from $241 \pm 65$ to $44 \pm 9 \mathrm{~mm} \mathrm{Hg}$ $(32.1 \pm 8.7$ to $5.9 \pm 1.2 \mathrm{kPa} ; p<0.01)$. Brief treatment with inhaled NO (20 ppm) abruptly decreased $\mathrm{PaCO}_{2}$ by $22 \%$ (Table 1), increased $\mathrm{PaO}_{2}$ (Fig. $1 A$ ), and decreased PVR by $39 \%$ (Fig. $1 B$ ). After discontinuing NO inhalation, gas exchange and hemodynamic parameters returned to baseline over $10 \mathrm{~min}$ (Fig. 1). Heart rate at baseline was $204 \pm 6$ bpm and did not significantly change over the study period. Systemic arterial pressure was 47 $\pm 3 \mathrm{~mm} \mathrm{Hg}(6.3 \pm 0.4 \mathrm{kPa})$ at baseline; measurements were lower than baseline after $30 \mathrm{~min}$ of ventilation $(37 \pm$ $4 \mathrm{~mm} \mathrm{Hg}, 4.9 \pm 0.5 \mathrm{kPa} ; p<0.05)$ and after the 20 -min NO treatment period $(37 \pm 4 \mathrm{~mm} \mathrm{Hg}, 4.9 \pm 0.5 \mathrm{kPa} ; p<$ $0.05)$. Left atrial pressure was higher than baseline measurements $(2.2 \pm 0.2 \mathrm{~mm} \mathrm{Hg}, 0.3 \pm 0.03 \mathrm{kPa})$ at $30 \mathrm{~min}$ of ventilation $(5.6 \pm 1.4 \mathrm{~mm} \mathrm{Hg}, 0.8 \pm 0.19 \mathrm{kPa} ; p<0.05)$ and at $60 \mathrm{~min}$ of ventilation $(3.6 \pm 0.5 \mathrm{~mm} \mathrm{Hg}, 0.5 \pm 0.07$ $\mathrm{kPa} ; p<0.05)$; however, after $60 \mathrm{~min}$ of ventilation, left

Table 1. Protocol 1: arterial blood gas data for 2-h study*

\begin{tabular}{lll}
\multicolumn{1}{c}{ Study period } & \multicolumn{1}{c}{$\mathrm{pH}$} & $\begin{array}{c}\mathrm{PaCO}_{2} \\
(\mathrm{kPa})\end{array}$ \\
\hline Baseline & $7.25 \pm 0.03$ & $6.1 \pm 0.3$ \\
$30 \mathrm{~min}$ & $7.36 \pm 0.03 \dagger$ & $3.7 \pm 0.5$ \\
$60 \mathrm{~min}$ & $7.28 \pm 0.04$ & $4.4 \pm 0.8$ \\
$90 \mathrm{~min}$ & $7.15 \pm 0.02 \dagger$ & $6.0 \pm 0.7$ \\
$120 \mathrm{~min}$ & $7.13 \pm 0.02$ & $6.0 \pm 0.7$ \\
$140 \mathrm{~min}$ (NO 20 ppm $\times 20 \mathrm{~min})$ & $7.17 \pm 0.03$ & $4.7 \pm 0.5 \ddagger$ \\
$150 \mathrm{~min}$ (off NO) & $7.11 \pm 0.03$ & $5.6 \pm 0.7$ \\
\hline
\end{tabular}

* Acute response to inhaled NO after $2 \mathrm{~h}$ of ventilation and blood gas data after withdrawing $\mathrm{NO}$ are also shown. $\mathrm{mm} \mathrm{Hg}=\mathrm{kPa} \cdot 7.5$.

$+p<0.01$ is previous study period.

$\ddagger p<0.05$ is previous study period. 

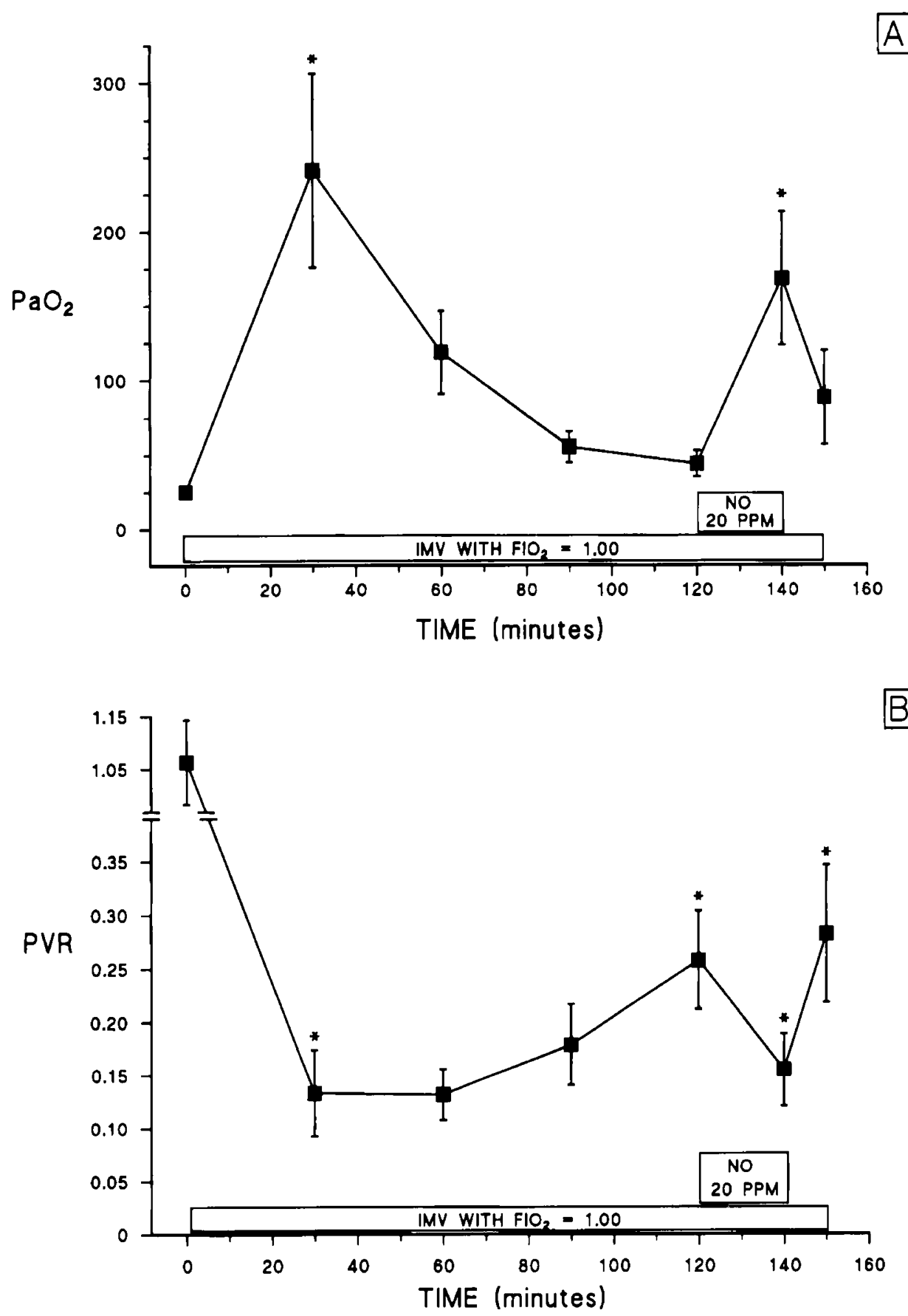

Figure 1. $A, \mathrm{PaO}_{2}(\mathrm{~mm} \mathrm{Hg})$ for the 2-h ventilation group in protocol 1, showing progressive decline in oxygenation over the 2-h study period, with a marked increase in $\mathrm{PaO}_{2}$ in response to low-dose inhaled $\mathrm{NO}$ at the 2 -h time point. Pao returns to baseline after $\mathrm{NO}$ is discontinued. ${ }^{*}, p<0.01$ vs 120 -min time point; $\mathrm{kPa}=\mathrm{mm} \mathrm{Hg} / 7.5 . B, \mathrm{PVR}\left[\mathrm{mm} \mathrm{Hg} \cdot(\mathrm{mL} / \mathrm{min})^{-1}\right]$ for the 2 -h ventilation group in protocol 1 , showing progressive increase in PVR over the 2-h intermittent mandatory ventilation period, with a marked decrease in PVR in response to low-dose inhaled NO at the 2-h time point. PVR returns to baseline after NO is discontinued. ${ }^{*}, p<0.01 \mathrm{vs} 120$-min time point.

atrial pressure was not different from baseline. PIP was decreased from $35 \mathrm{~cm} \mathrm{H} \mathrm{H}_{2} \mathrm{O}(3.4 \mathrm{kPa})$ to $30 \pm 2 \mathrm{~cm} \mathrm{H}_{2} \mathrm{O}$ $(2.9 \pm 0.2 \mathrm{kPa})$ by $60 \mathrm{~min}$ of ventilation in response to decreased $\mathrm{PaCO}_{2}$, and PEEP was decreased from $6 \mathrm{~cm}$ $\mathrm{H}_{2} \mathrm{O}(0.6 \mathrm{kPa})$ to $4.8 \pm 0.5 \mathrm{~cm} \mathrm{H}_{2} \mathrm{O}(0.5 \pm 0.05 \mathrm{kPa})$ by 60 $\mathrm{min}$ of ventilation in response to increased $\mathrm{PaO}_{2}$. There were no significant differences in ventilator rate or mean airway pressure during the study period.

\section{Protocol 2}

Effects of early inhaled NO treatment on pulmonary hemodynamics and gas exchange during $3 h$ of mechanical ventilation (NO treatment group, $n=6$; controls, $n=5$ ). Baseline arterial blood gas and hemodynamic measurements in treatment and Control animals were similar (Table 2). However, after $3 \mathrm{~h}$ of ventilation, $\mathrm{PaO}_{2}$ was 
Table 2. Protocol 2: arterial blood gas data for 3- $h$ continuous NO treatment in control group $(n=5)$ vs NO treatment group $(n=6) *$

\begin{tabular}{clccc}
\hline $\begin{array}{c}\text { Study } \\
\text { period }\end{array}$ & Study group & $\mathrm{pH}$ & $\mathrm{PaCO}_{2}(\mathrm{kPa})$ & $\mathrm{PaO}_{2}(\mathrm{kPa})$ \\
\hline Baseline & Control & $7.26 \pm 0.02$ & $6.0 \pm 0.3$ & $3.1 \pm 0.3$ \\
& NO treatment & $7.24 \pm 0.02$ & $6.3 \pm 0.4$ & $3.1 \pm 0.3$ \\
$60 \mathrm{~min}$ & Control & $7.24 \pm 0.04$ & $5.7 \pm 0.5$ & $12.3 \pm 3.7$ \\
& NO treatment & $7.28 \pm 0.05$ & $3.7 \pm 0.4 \dagger$ & $20.8 \pm 4.0$ \\
$120 \mathrm{~min}$ & Control & $7.15 \pm 0.04$ & $6.1 \pm 0.9$ & $10 \pm 5.3$ \\
& NO treatment & $7.12 \pm 0.05$ & $5.7 \pm 0.5$ & $11.7 \pm 3.1$ \\
$180 \mathrm{~min}$ & Control & $7.06 \pm 0.08$ & $8.5 \pm 1.5$ & $4.8 \pm 1.5$ \\
& NO treatment & $7.06 \pm 0.06$ & $6.4 \pm 0.3$ & $15.2 \pm 3.6 \dagger$ \\
\hline
\end{tabular}

$* \mathrm{~mm} \mathrm{Hg}=\mathrm{kPa} \cdot 7.5$.

$\dagger p<0.05 v s$ control group.

3.2-fold higher with NO treatment than in the control group, despite similar ventilator settings (Table 3). NO treatment attenuated the decline in $\mathrm{Q}_{\mathrm{LPA}}$ and the increase in PVR associated with prolonged mechanical ventilation (Fig. 2). At the end of the study, animals were killed, catheter positions were verified, and body weights were recorded. Body weight for the two groups of animals was not different $(1.95 \pm 0.09 \mathrm{~kg}$ with NO treatment; $1.85 \pm$ $0.12 \mathrm{~kg}$ in control).

\section{DISCUSSION}

We hypothesized that during tidal-volume mechanical ventilation with high inspired oxygen concentrations after delivery of extremely premature lambs, altered pulmonary vasoregulation leads to increased PVR, decreased pulmonary blood flow, and worsening gas exchange despite a good initial response to exogenous surfactant. We found that the pulmonary hypertension associated with severe HMD in the extremely premature lamb is responsive to exogenous NO, and that early and sustained treatment with low-dose NO in this model attenuates the decline in gas exchange and pulmonary perfusion during prolonged mechanical ventilation.

The premature fetus is characterized by both structural and functional pulmonary immaturity, including surfactant deficiency. Pulmonary immaturity and HMD lead to respiratory failure after premature delivery, and exogenous surfactant therapy can decrease the severity of the respiratory insufficiency (15). In some experimental mod-

Table 3. Protocol 2: ventilator settings 3-h IMV study; control group $(n=5)$ vs NO treatment group $(n=6)$

\begin{tabular}{clllcc}
\hline $\begin{array}{c}\text { Study } \\
\text { period }\end{array}$ & Study group & $\begin{array}{c}\text { PIP } \\
(\mathrm{kPa})\end{array}$ & $\begin{array}{c}\text { PEEP } \\
(\mathrm{kPa})\end{array}$ & $\begin{array}{c}\text { RATE } \\
(\text { breaths/min })\end{array}$ & $\begin{array}{c}\text { Paw } \\
(\mathrm{kPa})\end{array}$ \\
\hline Baseline Control & $3.4 \pm 0$ & $0.6 \pm 0$ & $30 \pm 0$ & $1.96 \pm 0$ \\
& NO treatment & $3.4 \pm 0$ & $0.6 \pm 0$ & $30 \pm 0$ & $1.96 \pm 0$ \\
$60 \mathrm{~min}$ & Control & $3.1 \pm 0.1$ & $0.5 \pm 0.1$ & $30 \pm 0$ & $1.76 \pm 0.1$ \\
& NO treatment & $3.2 \pm 0.1$ & $0.6 \pm 0$ & $30 \pm 0$ & $1.86 \pm 0.1$ \\
$120 \mathrm{~min}$ & Control & $3.1 \pm 0.1$ & $0.6 \pm 0.04$ & $34 \pm 4$ & $1.86 \pm 0.1$ \\
& NO treatment & $3.0 \pm 0.1$ & $0.5 \pm 0.02$ & $30 \pm 0$ & $1.76 \pm 0.1$ \\
$180 \mathrm{~min}$ & Control & $3.2 \pm 0.1$ & $0.6 \pm 0.04$ & $38 \pm 5$ & $1.86 \pm 0.1$ \\
& NO treatment & $3.2 \pm 0.1$ & $5.6 \pm 0.04$ & $35 \pm 5$ & $1.86 \pm 0.1$ \\
\hline
\end{tabular}

* $\mathrm{cm} \mathrm{H}_{2} \mathrm{O}=\mathrm{kPa} \cdot 10.2$. Paw, mean airway pressure. els of HMD, PVR falls in response to mechanical ventilation alone, and surfactant therapy does not change the direction or magnitude of systemic-to-pulmonary shunting across the patent ductus arteriosus $(16,17)$. However, progressive deterioration after surfactant therapy occurs in a subset of premature human newborns with HMD, leading to severe pulmonary hypertension with right-toleft shunting across the ductus arteriosus (18-21). Recent studies have shown that the association of pulmonary hypertension with severe HMD leads to increased mortality despite surfactant therapy (22).

The etiology of this apparent surfactant-failure has been elusive. Multiple mechanisms may be involved, including surfactant inactivation caused by alveolarcapillary leak and pulmonary edema, and the production of pulmonary vasoconstrictor agents or diminished endogenous vasodilator formation. Mechanical factors are known to contribute to the increase in pulmonary blood flow at birth. Changes in alveolar surface tension and perivascular tissue pressure $(23,24)$ and changes in pulmonary endothelial morphology (endothelial cell "flattening") also occur with the onset of ventilation $(25,26)$. It is likely that these structural changes in pulmonary vascular endothelial cells at birth are associated with functional changes such as augmentation of endogenous NO production, contributing further to pulmonary vasodilation (7). It is also possible that, after birth, the mechanical effects of rhythmic distention of the lung could alter endogenous NO formation by the immature pulmonary vascular endothelial cell, accounting for suboptimal responses to otherwise effective therapies for severe respiratory failure in prematurity, such as surfactant replacement. However, the effects of ventilation with hyperoxia on the endogenous production of vasoconstrictor substances (e.g. endothelin) and vasodilators (e.g. NO and prostaglandin $\mathrm{I}_{2}$ ) and the adverse effects of ventilation and hyperoxia on the structural integrity of the immature lung require further study.

These findings have potential implications for the clinical management of severe respiratory failure in premature infants. The newborn lamb at $115 \mathrm{~d}$ gestation develops profound respiratory failure despite treatment with exogenous surfactant and may not exemplify the potentially viable human born prematurely. However, despite the extreme pulmonary immaturity in this ovine model, the pulmonary circulation is markedly responsive to inhaled NO, suggesting a potential therapeutic role in the management of the preterm newborn with pulmonary hypertension. We speculate that the early use of lowdose inhaled NO could play a role in the management of the premature subject with severe respiratory failure unresponsive to exogenous surfactant therapy (27) by improving ventilation/perfusion matching and reducing PVR. However, we caution that little is known of the potential pulmonary and systemic toxicities that could occur in the premature subject exposed to inhalational NO, and studies designed to carefully assess such toxicities are essential before routine clinical application. 

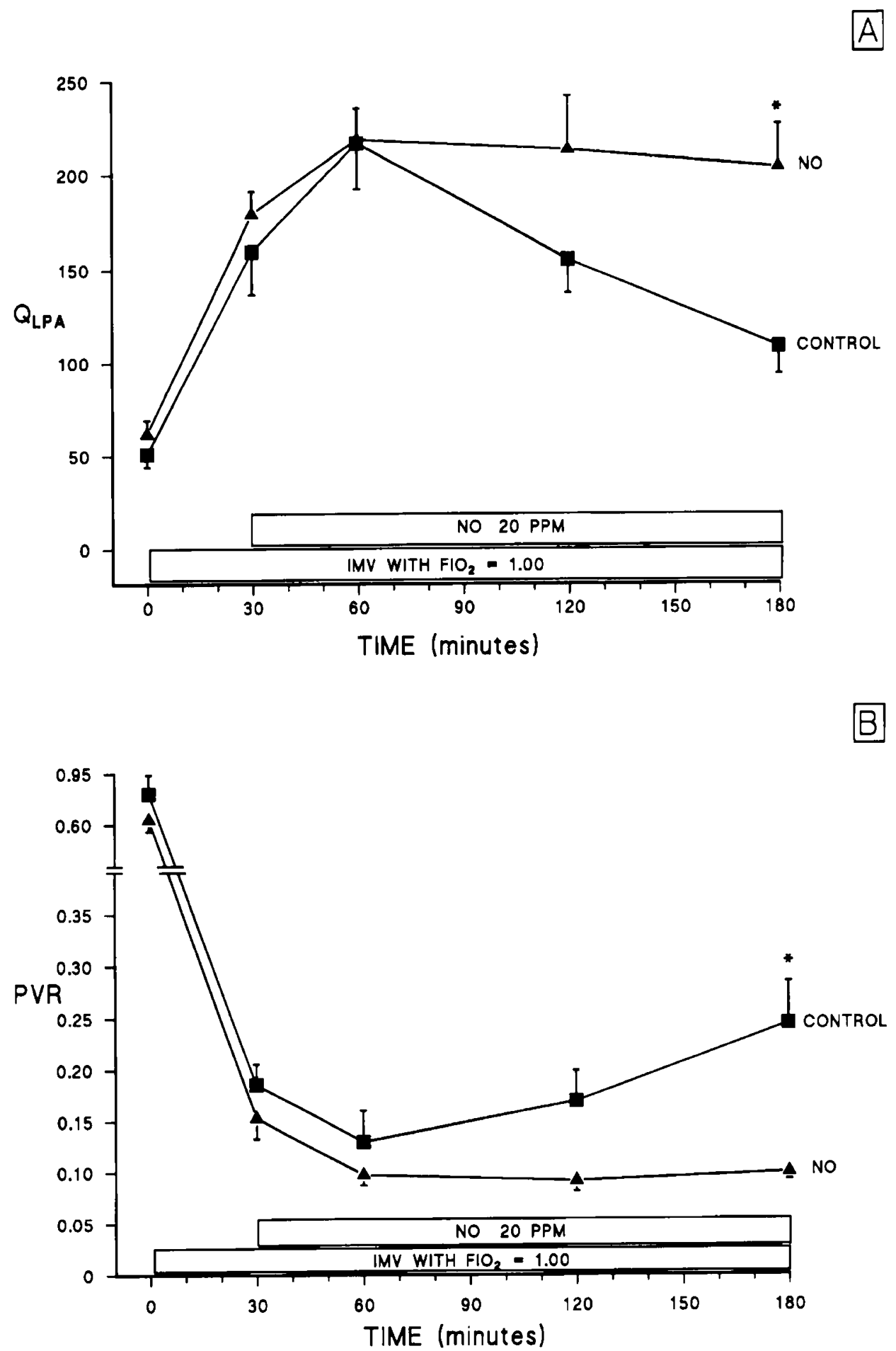

Figure 2. $A, \mathrm{Q}_{\mathrm{LPA}}(\mathrm{mL} / \mathrm{min})$ for the NO treatment $v$ s control groups in protocol 2. Low-dose NO treatment caused sustained increase in $\mathrm{Q}_{\mathrm{LPA}}$ over the entire 3-h study period compared with controls. ${ }^{*}, p<0.05$, NO treatment group vs control group at 3-h time point. $B$, PVR [mm $\mathrm{Hg} \cdot(\mathrm{mL} / \mathrm{min})^{-1}$ ] for the NO treatment $v s$ control groups in protocol 2 . Low-dose NO treatment caused sustained decrease in PVR over the entire 3-h study period compared with controls. ${ }^{*}, p<0.05$, NO treatment group $v s$ control group at 3-h time point.

Acknowledgments. The authors thank I.-Da Fan and Y. Fan Chang for technical support and E. A. Egan, M.D., for kindly providing the surfactant product.

\section{REFERENCES}

1. Abman SH, Chatfield BA, Hall SL, McMurtry IF 1990 Role of endotheliumderived relaxing factor during transition of the pulmonary circulation at birth. Am J Physiol 259:H1921-H1927
2. Kinsella JP, McQueston JA, Rosenberg AA, Abman SH 1992 Hemodynamic effects of exogenous nitric oxide in ovine transitional pulmonary circulation. Am J Physiol 262:H875-H880

3. Roberts JD, Chen T, Kawai N, Wain J, Dupuy P, Shimouchi A, Bloch K, Polaner D, Zapol WM 1993 Inhaled nitric oxide reverses pulmonary vasoconstriction in the hypoxic and acidotic newborn lamb. Circ Res 72:246-254

4. Zayek M, Cleveland D, Morin FC 1993 Treatment of persistent pulmonary hypertension in the newborn lamb by inhaled nitric oxide. J Pediatr 122:743750 
5. Roberts JD, Polaner DM, Lang P, Zapol WM 1992 Inhaled nitric oxide in persistent pulmonary hypertension of the newborn. Lancet 340:818-819

6. Kinsella JP, Neish SR, Shaffer E, Abman SH 1992 Low-dose inhalational nitric oxide in persistent pulmonary hypertension of the newborn. Lancet 340:819-820

7. Kinsella JP, Neish SR, Ivy DD, Shaffer E, Abman SH 1993 Clinical responses to prolonged treatment of persistent pulmonary hypertension of the newborn with low doses of inhaled nitric oxide. J Pediatr 123:103-108

8. Finer NN, Etches PC, Kamstra B, Tierney AJ, Peliowski A, Ryan CA 1994 Inhaled nitric oxide in infants referred for extracorporeal membrane oxygenation: dose response. J Pediatr 124:302-308

9. Jobe AH 1992 Surfactant in the perinatal period. Early Hum Dev 26:57-62

10. Kinsella JP, Ivy DD, Abman SH 1994 Maturational changes in endotheliumderived nitric oxide activity and responses to exogenous nitric oxide in the developing pulmonary circulation. Am J Physiol (in press)

11. Jobe A, Ikegami M 1984 The prematurely delivered lamb as a model for studies of neonatal adaptation. In: Nathanielsz PW (ed) Animal Models in Fetal Medicine. Perinatology Press, New York, pp 1-30

12. Jobe A, Ikegami M, Glatz T, Yoshida Y, Diakomanolis E, Padbury J 1981 The duration and characteristics of treatment of premature lambs with natural surfactant. J Clin Invest 67:370-375

13. Cummings JJ, Holm BA, Hudak ML, Hudak BB, Ferguson WH, Egan EA 1992 A controlled clinical comparison of four different surfactant preparations in surfactant-deficient preterm lambs. Am Rev Respir Dis 145:999_ 1004

14. Abman SH, Shanley PF, Accurso FJ 1989 Failure of postnatal adaptation of the pulmonary circulation after chronic intrauterine pulmonary hypertension in fetal lambs. J Clin Invest 83:1849-1858

15. Jobe AH 1993 Pulmonary surfactant therapy. N Engl J Med 328:861-868

16. Kinsella JP, Gerstmann DR, de Lemos RA 1991 Circulatory changes following premature delivery in a baboon model of hyaline membrane disease. Am J Physiol 261:H1148-H1154
17. Kinsella JP, Gerstmann DR, Gong AK, deLemos RA 1991 Ductal shunting and effective systemic blood flow following single dose surfactant treatment in the premature baboon model of hyaline membrane disease. Biol Neonate 60:283-291

18. Chu J, Clements JA, Cotton EK, Klass MH, Sweet AY, Tooley WH 1967 Neonatal pulmonary ischemia. Part 1: clinical and physiological studies. Pediatrics 40:709-782

19. Stahlman M, Blankenship WJ, Shepard FM, Gray J, Young WC, Malan AF 1972 Circulatory studies in clinical hyaline membrane disease. Biol Neonate 20:300-320

20. Evans NJ, Archer LNJ 1991 Doppler assessment of pulmonary artery pressure and extrapulmonary shunting in the acute phase of hyaline membrane disease. Arch Dis Child 66:6-11

21. Skinner JR, Boys RJ, Hunter S, Hey EN 1992 Pulmonary and systemic arterial pressure in hyaline membrane disease. Arch Dis Child 67:366-373

22. Walther FJ, Benders MJ, Leighton JO 1992 Persistent pulmonary hypertension in premature neonates with severe respiratory distress syndrome. Pediatrics 90:899-9(14

23. Nieman GF, Hakim TS, Bredendburg CE 1988 Effect of increased alveolar surface tension on segmental pulmonary vascular resistance. J Appl Physiol 64:154-161

24. Bland RD, Hansen TN, Habakern CM, Bressack MA, Hazinski TA, Raj JU, Goldberg RB 1982 Lung fluid balance in lambs before and after birth. J Appl Physiol 53:992-1004

25. Haworth SG, Hislop AA 1981 Adaptation of the pulmonary circulation to extra-uterine life in the pig and its relevance to the human infant. Cardiovasc Res 15:109-119

26. Hall SM, Haworth SG 1986 Normal adaptation of pulmonary arterial intima to extrauterine life in the pig: ultrastuctural studies. J Pathol 149:55-66

27. Abman SH, Kinsella JP, Schaffer MS, Wilkening RB 1993 Inhaled nitric oxide therapy in a premature newborn with severe respiratory distress and pulmonary hypertension. Pediatrics 92:606-609 